\title{
Warship Combat Mission Profile Model
}

\author{
WANG Lei ${ }^{1, a}$, SHEN Zhansheng ${ }^{1, a}$,QIAN Jia ${ }^{1, a}$ \\ ${ }^{1}$ Dept. of Missiles \& Shipboard Gunnery, Dalian Naval Academy, Dalian 116018, China \\ aspriter_007@163.com
}

\begin{abstract}
Keywords: combat mission profile; shipborne weapons; three-dimensional model
Abstract. In view of the ship-borne weapons and equipment carries out the need of combat mission under the condition of high and new technology, in order to clarify the relationship between the factors influencing the weapon equipment operational effectiveness, depict the whole operational process in detail, established the general 3D model of naval ship combat mission profile. From time dimension, equipment dimension and combat criterion dimension, the combat process is fully described and has universality.
\end{abstract}

\section{Introduction}

The future war is a comprehensive counterbalance between the high-tech equipment system. The combat district, combat time domain, combat styles, operational principles, operational methods, and operational environments will be highly uncertain. In order to improve the shipborne weapons mission success and operational effectiveness, combat task details must be accurate and complete depiction, and detailed description from receive tasks to post-war evaluation summary of the whole process of environmental impact, equipment reliability, equipment operation, operational principle, operational method and assessment criteria, and other factors, and to clarify the links between various influencing factors. The combat mission profile of shipborne weapons and equipment is an integral part of the equipment mission section.

The mission profile is defined as: "the sequence of events and circumstances experienced by the product during the completion of the specified tasks" [1]. The weaponry combat mission profile refers to the general term for events and circumstances that have been experienced during the period from combat readiness to the completion of a typical combat mission. The combat mission profile of the weapon equipment covers every task that it can perform. Its rules on the task from beginning to end have been through a series of events and environmental conditions on time sequence was described, and each task is determined with temporal phase duration of weapons and equipment tasks, events, and conditions of use.

\section{Mission profile description}

Mission profile is usually used to define the main tasks of the equipment, working status, operating time, working order, maintenance plan, and environment[2]. From the definition of the task section, it is necessary to define four aspects, such as the specified time, the specified environment, the specified product and the specified event. According to the combat mission undertaken by the weapon equipment, the elements of the combat mission section are mainly described from the time, region, environment, compilation and planning of the mission[3] [4].

\section{Mission time}

Mission time contains the start and end times of the task. The tasks can be divided into several sub-phases according to the task time period. For example, the ship combat mission profile can be reduced to four stages of voyage, combat, evacuation and return. This paper will only consider the mission profile of the warship combat phase.

\section{Mission area}

The mission area refers to the geographical location and geographical range of the ship's operations. Latitude and longitude are used to describe the mission area. When the task time and the task area are identified, the task environment is determined. 


\section{Mission environment}

In surface ships against air defense, mission environment is a description of the external environmental factors that affect the operational effectiveness. It mainly includes the sea battle field environment such as electromagnetism, meteorology, water sound, day and night and sea condition.

\section{Mission structure}

Mission structure requires a description of the combat unit and command relationship, which can be described by the tree structure. The surface ship combat system participates in the combat units with the detection system, the accusation system and the weapon system. The corresponding command relation of each combat unit constitutes the mission structure.

\section{Mission planning}

Mission planning refers to the planning of completing the action of each combat unit within the task time period. Ships carry weapons against air and sea combat, each unit of the weapon system has different specific tasks. In the specified time, it is necessary to optimize the profile of fixed tasks efficiently.

\section{Ship combat mission profile design}

\section{Analysis of typical naval combat mission process}

Before the ship carries out the mission, there is usually a shooting preparation and shooting observation. A series of preparations for the operation is called combat readiness. This time period usually refers to the first weapon launch from receiving combat missions. Such as research and analysis, to formulate operational plans, organizing exercises, prewar preparation and inspection of weapons, instruments and ammunition, preparation of ballistic weather conditions, etc. But from the point of view of shooting, the center of the shooting preparation is to calculate the firing and target the shooting.

After the preparation is completed, when encountering an enemy ship, first determine the location of the target or the side angle, the distance between the opposing sides and the side angle of the ship. Rapidly occupying the position, the ship is able to gain advantageous position through observation and tactical maneuver, is an important condition to defeat the enemy. Both sides are based on task performance and visibility, other ships, etc. Occupation of the other party is difficult to play all the shipborne weapons power Angle, opened fire on the distance for yourself and for each other or to death. The ship's side angle requires the use of the entire ship or fleet of shipborne weapons in the course of the combat and reduces the impact of the wave on the target.

After occupying the advantageous position of attack, the shipborne weapon system began to instruct the target and organize the fire. And then we're going to track it. Search, capture, and track targets. After determining the position, start the fire control solution, control the artillery fire, conduct shooting correction, and complete the shooting. Here, in order to quantize the firing preparation and firing observation, the combat effectiveness of the shipborne weapon was quantified by combining the accuracy and level of the firing preparation and the amount of shooting deviation.

\section{Combat mission profile establishment process}

The process of determining the operational use profile is a precise definition of the mission task of the equipment. Or the process of specifying the specific operational conditions required by the objectives of the equipment. Determine the combat mission profile, the tasks that define the equipment stage, operation mode, operation function, success criteria and task time, environmental stress, and under the environmental stress time, the limits on maintenance, etc.

Step 1, the first step is to convert the combat use requirements of the weapon equipment into a series of events, which are arranged in a number of stages according to the sequence of events. The multi-tasking capability of complex weapon equipment needs to be combined with multiple profiles to illustrate mission capability and requirements. When various tasks are possible, each task is considered as a separate sequence of events. Form the first dimension of the mission profile: time dimension. The time dimension is staged. 
Step 2, when various task phases are identified, task analysis should be performed for each task phase. Lists the various operating modes of each major equipment in each task phase and various execution functions in each operation mode, and relates to the related task requirements. Form the second dimension of the mission profile: equipment dimension.

Step 3, can use task analysis information subsystem of each equipment listed in each stage and what we need in each operation mode of executive function, hardware and software, the execution time and success criteria, under environmental stress, task cycle time, maintenance restrictions, etc.

Step 4,The operational requirements, security requirements and environmental conditions of the identified equipment subsystem are further refined to the equipment level. As the specific operation of equipment and equipment, the basic requirements of operational effectiveness should be given. Form the third dimension of the mission profile: criterion dimension.

\section{The model of ship combat mission profile}

According to the working principle and working procedure of the shipborne weapon system, typical combat mission profile can be established for typical combat missions. As shown in Fig. 1.

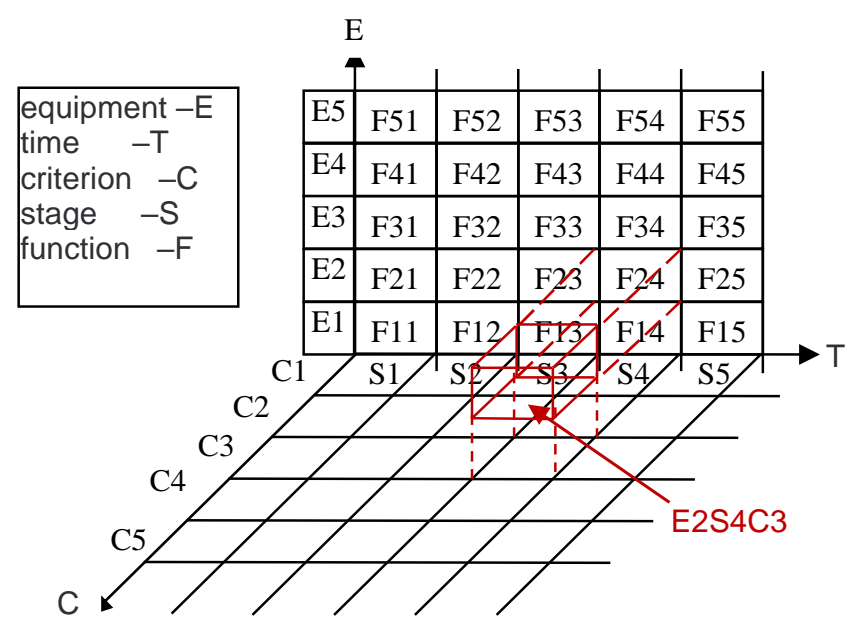

Fig.1.Combat mission profile 3d model

The 3d combat mission profile model is composed of time dimension, equipment and standard dimension. The combat mission section is divided into several independent sub-task stages according to the process of the combat mission, and the detailed degree of the task phase can be determined according to the actual demand. Equipment dimension refers to the functions and functions of various subsystems or devices that are composed of different tasks and sub-tasks. The criterion dimension is to show the operation steps and related requirements for the corresponding tasks in different task stages and sub-tasks.

For example, the E2S4C3 part in figure 1 refers to the operation and use method of equipment 2 under the constraint of rule 3 in stage 4.

According to the detailed requirements of task segmentation and operational process details, it can be further established according to the general model to establish level 2, 3 or even more detailed multi-level combat mission profile.

\section{Conclusion}

The 3D combat mission model of warship has changed the description of environmental stress and equipment reliability in the past, which is detailed in three aspects from combat mission, environment and equipment operation. Moreover, through the establishment of 3D model, the limitation of 2D profile display is changed, and the influence of each factor is more directly reflected. The $3 \mathrm{~d}$ combat mission profile model of the ship is universal and can be applied to the combat mission profile analysis of all shipborne weapon systems. It can be applied to the combat mission profile analysis of 
any granularity requirement. The 3D combat mission profile model of shipborne weapon system has the characteristics of comprehensive, practical, strong and easy to use.

\section{References}

[1] Yiqun Zhi,ZhangJilei. A study on typical combat mission profile of a self-propelled gun-howitzer system [J]. Journal of artillery launch and control, 1998(1).

[2] Shi Jianrong, Wang Xiaoxia. Equipment life environment profile and mission profile [J].Equipment environment engineering, vol 7, 2010.4: 18-20.

[3] Tan Qi, Jiang Yongguang, mo xian. Research on reliability test mission of military communication network [J]. Information security and communication confidentiality, 2010.4: 53-55.

[4] Yu Jianjian, Zeng Benyin. Method of using mission profile for helicopter flight [J]. Helicopter technology, vol 138, 2004(2) 